\title{
Tobacco Use Among Reproductive Age Women in Ethiopia: Evidence from the National Health Survey
}

This article was published in the following Dove Press journal: Substance Abuse and Rehabilitation

\section{Tilahun Abdeta (D) Gari Hunduma (iD)}

Department of Psychiatry, School of Nursing and Midwifery, College of Health and Medical Sciences, Haramaya University, Harar, Ethiopia
Correspondence: Tilahun Abdeta Department of Psychiatry, School of Nursing and Midwifery, College of Health and Medical Sciences, Haramaya University, PO Box 235, Harar, Ethiopia Tel $+2519176497 / 4$

Fax +25I25666808I

Email tilahunabdeta@gmail.com
Purpose: To assess the prevalence and determinants of current tobacco use among reproductive-age women in Ethiopia.

Methods: A cross-sectional study was conducted by utilizing secondary data taken from the Ethiopian Demographic Health Survey of 2016. Descriptive statistics and logistic regressions were used to analyze the data. The odds ratio with a $95 \%$ confidence interval was considered to interpret associations and a significant association was stated at a $p$-value $<0.05$.

Results: The overall magnitude of current tobacco use was $1.4 \%(\mathrm{n}=217)$. Majority of them $59.91 \%(n=130)$ smoke cigarettes and followed by smoking gaya $43.32 \%(n=94)$. Higher prevalence was found among participants from Gambella 44.24\% $(\mathrm{n}=96)$, Benishangul.59\% $(n=36)$ and afar regions $13.36 \%(n=29)$. Age group of $25-34$ years $[$ AOR $=2.78 ; 95 \% \mathrm{CI}$ : $1.69,4.57)]$, age group of $\geq 35$ years $[\mathrm{AOR}=4.24 ; 95 \% \mathrm{CI}: 2.54,7.07)]$, followers of protestant religion $[\mathrm{AOR}=2.36 ; 95 \% \mathrm{CI}: 4.17,9.42]$, Islamic religion $[\mathrm{AOR}=3.92 ; 95 \%$ $\mathrm{CI}: 2.16,7.11]$, and traditional religion $[\mathrm{AOR}=16.23 ; 95 \% \mathrm{CI}: 8.33,31.61$ ], being in poorest wealth index $[\mathrm{AOR}=15.78 ; 95 \% \mathrm{CI}$ : 7.38, 33.70], poorer wealth index $[\mathrm{AOR}=5.85 ; 95 \%$ CI: 2.64, 12.97], middle wealth index [AOR $=3.61 ; 95 \% \mathrm{CI}: 1.57,8.29$ ], and richer wealth index $[\mathrm{AOR}=2.48 ; 95 \% \mathrm{CI}: 1.10,5.85]$, who were never in union $[\mathrm{AOR}=0.31 ; 95 \% \mathrm{CI}$ : $0.14,0.67]$, ever drinking alcohol $[\mathrm{AOR}=5.44 ; 95 \% \mathrm{CI}: 3.71,7.95]$ and ever chewing khat [AOR $=7.59 ; 95 \% \mathrm{CI}: 4.99,11.55]$ were factors associated with current tobacco use.

Conclusion: Women used tobacco in different forms, and its distribution varies across Ethiopian regional states. The concerned body needs to give attention to the identified associated factors and regions with higher tobacco use.

Keywords: tobacco use, reproductive age women, Ethiopia

\section{Background}

Tobacco is one of the vastly used substances and a top cause of escapable morbidity and mortality worldwide. ${ }^{1,2}$ The deaths of around seven million persons annually are due to direct tobacco use, and about 600,000 deaths as of secondary smoke. ${ }^{3}$

Globally, tobacco use among men is gradually decreasing. However, it is increasing speedily among women especially in developing countries. ${ }^{4,5}$ Tobaccolinked deaths might increase from 1.5 million in 2004 to 2.5 million through 2030 among women aged $\geq 20$ years, and nearly $75 \%$ of this anticipated death will be happening in low- and middle-income countries. ${ }^{6}$

In Africa, both smoking rates and tobacco-linked deaths are increasing as the prevalence was increased from $9.8 \%$ in 2015 to $13.9 \%$ in 2016 as well as tobacco- 
related death was increased from 150,000 reported in 1990 to over 215,000 in $2016 .^{7}$

In Ethiopia, there was no study about tobacco use specifically among reproductive-age women. However, a nationwide study revealed the prevalence of current tobacco use among adult populations age $15-59$ years was $4.1 \%$ ( $8.1 \%$ in men and $0.8 \%$ in women). ${ }^{8}$ Additionally, Ethiopia Global Adult Tobacco Survey 2016, reported, 5.0\% (3.4 million) of adults were current users of tobacco products $(8.1 \%$ among men and $1.8 \%$ among women). ${ }^{9}$ In Ethiopia, tobacco is used in different forms including smoking cigarettes, smoking pipeful of tobacco, chewing tobacco, smoking snuff, smoking shisha, and smoking Gaya. ${ }^{8}$ Among these smoking cigarettes, smoking shisha, and smoking Gaya are the commonest form of tobacco use. Despite the high prevalence of tobacco-related diseases including lung cancer, cardiac diseases, and duodenal ulcers in Ethiopia, tobacco use is socially acceptable. ${ }^{10}$

Tobacco use affects women's physical and psychological health, socio-economic status, and their family's health. ${ }^{11}$ Women who consume tobacco are at more risk of menstrual, reproductive health problems, and chronic diseases. ${ }^{11}$ Tobacco use at the time of pregnancy could cause adverse pregnancy outcomes and impair child growth and development. ${ }^{12-14}$ It was also, significantly associated with Low Birth Weight, reduced birth Length, stillbirth, neonatal death, and sudden infant death syndrome (SIDS). Breastfeeding is of shorter duration among women who smoke than among non-smokers due to smokers may produce less breast milk than non-smokers. ${ }^{15,16}$

WHO intended the Framework Convention on Tobacco Control (WHO FCTC) as a global reply to tobacco increases. ${ }^{17}$ Ethiopia signed the convention to ratify the WHO Framework Convention on Tobacco Control (FCTC) in 2004 and ratified in 2014 and gave the mandate for implementing the WHO FCTC to the Ethiopian Food, Medicine and Healthcare Administration and Control Authority (FMHACA). Subsequently, FMHACA issued the National Tobacco Control Directive (NTCD 2015) on 21 March $2015 .^{18}$ This legislation aimed at reducing demand, discouraging tobacco use, and reducing the supply of tobacco products. The NTCD 2015 prohibits, among other things, the sale of flavored tobacco products including menthol, the sale of tobacco products to a person under the age of 18 years, and bans all forms of tobacco advertising, promotion, and sponsorship. However, as many Africans did not realize their responsibilities charted in the WHO FCTC, ${ }^{19}$ NTCD 2015 legislation has major gaps like allowing smoking designated rooms in some prohibited places.
Previous studies showed the association between tobacco use among reproductive-age women and variables including the accessibility of tobacco products, illiteracy, more than two parity, advertising and promotion of tobacco products, stress, parental hostility, strictness, and family conflict, level of parental supervision, involvement, or attachment, parental or other household members' smoking, peer smoking, perceived norms and prevalence of smoking, and perceived peer attitudes toward smoking. ${ }^{20,21}$ In Ethiopia, even if there was no study regarding tobacco use among reproductive-age women, the community-based studies revealed that tobacco use has an association with variables like male gender, increasing age, being a follower of Islam, being in formal employment, having experience of child death, chewing khat and geographic regions. ${ }^{8,22,23}$

In the current study analysis, we included factors that comprise sociodemographic variables (age, religion, current marital status, residence, educational status, wealth index, and occupation within the last 12 months), and ever substance use (drinking alcohol and chewing khat). We included these variables because we hypothesized that they are good determinants of current tobacco use as we read from the previous studies. ${ }^{8,20-23}$ Also, these variables were accessible from EDHS of 2016 Dataset. However, we have missed some important variables like the history of mental illness, parental hostility, strictness, and family conflict, level of parental supervision, involvement, or attachment, and partners or other household members' tobacco use because we could not get them from EDHS of 2016 Dataset.

The other important point is, using a smokeless form of tobacco (SLT) had a lack of data informing their popularity, and because of this, it has monitored in many fewer countries than smoking tobacco. ${ }^{1}$ Similarly, in Ethiopia, there is no data analyzed at national and regional levels regarding tobacco use among reproductive-age women. Having data on the magnitude of different forms of tobacco and factors associated with overall current tobacco use is essential to evaluate and strengthen the existing national tobacco control policies of Ethiopia especially, among a special group of populations like reproductiveage women. ${ }^{24}$

Therefore, this study was designed to assess the prevalence of different common forms of tobacco use and to identify determinants of the overall current tobacco use among reproductive-age women in Ethiopia using secondary data taken out from the EDHS 2016. 


\section{Methods}

\section{Data Sources and Setting}

We conducted a cross-sectional study utilizing secondary data taken out from the most recent Ethiopian Demographic Health Survey of 2016 (EDHS 2016), which is a national survey conducted across the nine Ethiopian regional states and two administrative cities and composed data on health, demographic, and socioeconomic indicators. Ethiopia is one of the Sub-Saharan African Countries located in the Horn of Africa, and is bordered by Eritrea to the north, Sudan to the west, Kenya to the south, Somalia to the east, and Djibouti to the northeast. ${ }^{25}$ EDHS 2016 was the fourth and most recent data in Ethiopia and collected from January to June 2016. The survey was conducted by the Central Statistical Agency (CSA) using a two-stage stratified sampling technique. In the first stage, regions of the country were stratified into urban and rural settings. Then, in the second stage representative households were selected and the survey interviewer interviewed only the preselected households without replacement. For this study, all reproductive-age women of 15 to 49 years old samples $(n=15,683)$ of the 2016 EDHS were included. The questionnaires were adapted by EDHS from the DHS Program's standard Demographic and Health Survey questionnaires to reflect the population and health-related issues relevant to Ethiopia. The details about the DHS methodology are published elsewhere, ${ }^{26,27}$ and also available at http://www.dhsprogram.com/. In this study to make the article more objective, we had read the STROBE statement-checklist of items that should be included in reports of cross-sectional studies and we have addressed each thing listed on the check list. ${ }^{28}$

\section{Study Variables Dependent Variable}

In our study, the dependent variable was "current tobacco use", which means when participants used at least one form of tobacco enumerated in the 2016 EDHS data during the survey year and the respondents were asked a single question if they currently use any type of tobacco during the survey year. There were seven different forms of tobacco use in the 2016 EDHS database:

smoking cigarettes (yes/no), smoking pipeful of tobacco (yes/no), chewing tobacco (yes/no), smoking snuff (yes/ no), smoking shisha (yes/no), smoking Gaya (yes/no) and any other methods of tobacco use. (yes/no)
Then, "No" answers of each tobacco form were recorded as " 0 " and measured as participants were "non-current tobacco users". Whereas "yes" answers were recorded as " 1 " and taken as they were "current tobacco users". Then we added all "no" and "yes" replies that give a score of 0 to 7. Finally, zero scores were labeled as "non-current tobacco users", whereas from 1 to 7 were labeled as "current tobacco users".

\section{Independent Variables}

Independent variables were: age, place of residence, administrative regions, religion, educational status, wealth index, occupation within the last 12 months, current marital status, life time alcohol use (participants who had ever drunk any amount of alcohol at least once in their lifetime), and life time chewing khat (participants who had ever used any amount of khat at least once in their lifetime).

\section{Statistical Analysis}

We used descriptive statistics to describe sociodemographic characteristics of study participants, the overall magnitude of current tobacco use, and also to show the distribution of tobacco use across administrative regions. To identify associated factors, we did a logistic regression analysis. Variables with a p-value $<0.25$ in bivariate, were included in the multivariable model. Finally, after controlled the potential confounders in multivariable analysis, variables with a $p$-value $<0.05$ were concluded as statistically associated with the outcome variable. We calculated the odds ratio with a $95 \%$ confidence interval to identify the magnitude of association and statistical significance.

\section{Results}

\section{Socio-Demographic and Other Substance Use Characteristics of Respondents}

Our study included a total of 15,683 reproductive age women age 15 to 49 years old. Their mean age (SD) was 27.94+-9.16 years. Nearly two-thirds of the participants $(65.9 \%)$ were rural residents. Of the participants, 7033 (44.8\%) have no formal education. More than a quarter (26.3\%) of respondents were found within the poorest wealth index. The majority $(62.6 \%)$ were married, and $7.2 \%(\mathrm{n}=1122)$ of the total participants were currently pregnant. About 10,011 (63.8\%) of the participants had no occupation (not working) in the last 12 months. About $5167(32.9 \%)$ and $1556(9.9 \%)$ of the respondents reported that they had ever used alcohol and ever chewed khat, respectively (Table 1). 
Table I Socio-Demographic and Other Substance Use Characteristics of Reproductive Age Women, Ethiopia DHS $2016(N=15,683)$

\begin{tabular}{|c|c|c|}
\hline Variables & Frequency & Percentage \\
\hline \multicolumn{3}{|l|}{ Age group (in years) } \\
\hline$<25$ & 6401 & 40.8 \\
\hline $25-34$ & 5086 & 32.4 \\
\hline$\geq 35$ & 4196 & 26.8 \\
\hline \multicolumn{3}{|l|}{ Residence } \\
\hline Urban & 5348 & 34.1 \\
\hline Rural & 10,335 & 65.9 \\
\hline \multicolumn{3}{|l|}{ Administrative regions } \\
\hline Tigray & 1682 & 10.7 \\
\hline Afar & 1128 & 7.2 \\
\hline Amhara & 1719 & 11.0 \\
\hline Oromia & 1892 & 12.1 \\
\hline Somali & $|39|$ & 8.9 \\
\hline Benishangul & 1126 & 7.2 \\
\hline SNNPR & 1849 & 11.8 \\
\hline Gambella & 1035 & 6.6 \\
\hline Harari & 906 & 5.8 \\
\hline Addis Ababa & 1824 & 11.6 \\
\hline Dire Dawa & $|13|$ & 7.2 \\
\hline \multicolumn{3}{|l|}{ Educational status } \\
\hline No education & 7033 & 44.8 \\
\hline Primary & 5213 & 33.2 \\
\hline Secondary & 2238 & 14.3 \\
\hline Above & 1199 & 7.6 \\
\hline \multicolumn{3}{|l|}{ Religion } \\
\hline Orthodox & 6413 & 40.9 \\
\hline Protestant & 2814 & 17.9 \\
\hline Muslim & 6209 & 39.6 \\
\hline Others including traditional religion & 247 & 1.6 \\
\hline \multicolumn{3}{|l|}{ Wealth index } \\
\hline Poorest & 4122 & 26.3 \\
\hline Poorer & 2596 & 16.6 \\
\hline Middle & 2848 & 18.2 \\
\hline Richer & 2811 & 17.9 \\
\hline Richest & 3306 & 21.1 \\
\hline \multicolumn{3}{|l|}{ Current marital status } \\
\hline Never in union & 4278 & 27.3 \\
\hline Married & 9824 & 62.6 \\
\hline Widowed & 451 & 2.9 \\
\hline Divorced & 878 & 5.6 \\
\hline Separated & 252 & 1.6 \\
\hline \multicolumn{3}{|l|}{ Occupation within the last 12 months } \\
\hline No occupation (not working) & 10,011 & 63.8 \\
\hline Has occupation (working) & 5672 & 36.2 \\
\hline
\end{tabular}

(Continued)
Table I (Continued).

\begin{tabular}{|l|c|c|}
\hline Variables & Frequency & Percentage \\
\hline Ever drunk alcohol & & \\
No & 10,516 & 67.1 \\
Yes & 5167 & 32.9 \\
\hline Ever chewed khat & & \\
No & 14,127 & 90.1 \\
Yes & 1556 & 9.9 \\
\hline
\end{tabular}

\section{The Prevalence of Current Tobacco Uses Among Reproductive-Age Women in Ethiopia}

The overall magnitude of all forms of current tobacco uses among 15,683 reproductive age women was $1.4 \%$ (95\% CI: $1.28,1.52)$. The two hundred seventeen respondents reported that they have currently used at least one type of tobacco during the survey year and the left 15,466 participants did not use it. Out of the current tobacco users, the majority (59.91\%) smoke cigarettes and followed by smoking Gaya (43.32\%) and chewing tobacco (23.5\%) (Figure 1).

About $58.46 \%$ of the respondents who were smoking cigarettes smoke some days, and the remaining $41.54 \%$ smokes every day. Out of the two hundred seventeen (217) current tobacco users, the prevalence was higher among reproductive-age women of the Gambella region with $44.24 \%$ and followed by Benishangul (16.59\%) and Afar regions $(13.36 \%)$. However, there were no reproductive-age women who reported current tobacco use in Tigray regional state (Table 2).

\section{Factors Associated with Current Tobacco Use Among Reproductive-Age Women in Ethiopia}

In bi-variable analyses, at $\mathrm{p}$-value $<0.25$, we found that all variables were associated with current tobacco use. However, in the final multivariate logistic regression model, old age group, poorest wealth index, traditional religion followers, never in a union, ever used alcohol, and ever chewed khat, were remained associated factors of current tobacco use at a p-value of $<0.05$.

As the age of reproductive age women increased, the odds ratios of current tobacco use also increased. Women 


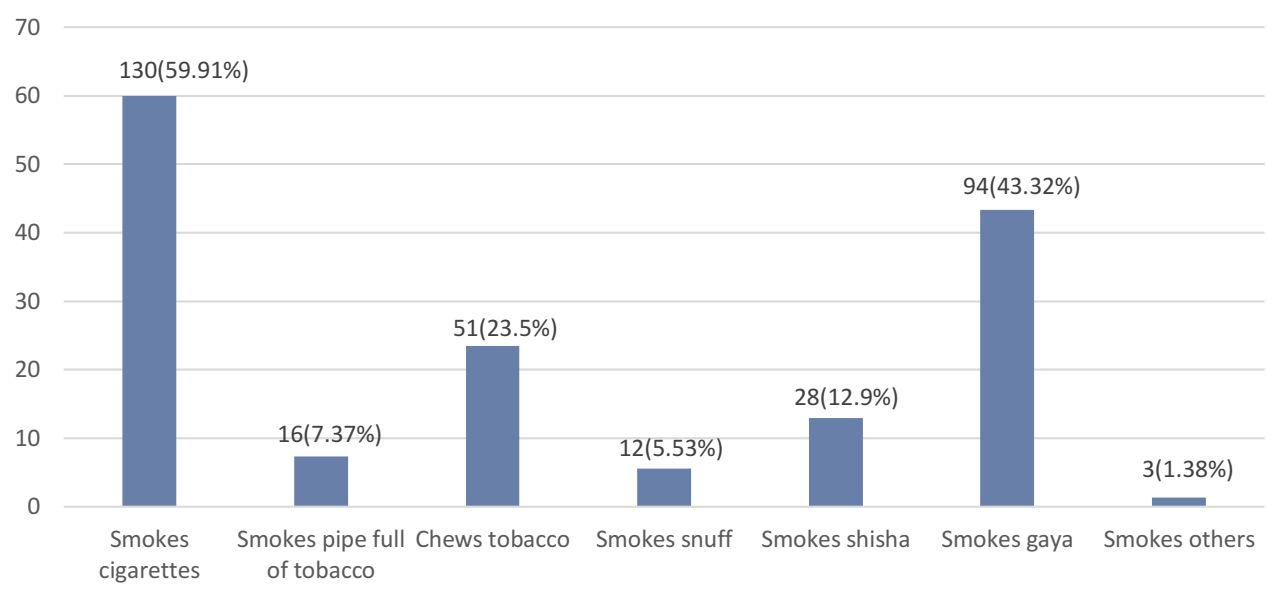

Figure I Percentage distribution of all common forms of tobacco use among reproductive-age women in Ethiopia ( $N=\mid 5,683)$, Ethiopian Demographic Health Survey 2016.

of age 25-34 years [AOR $=2.78 ; 95 \%$ CI: $1.69,4.57)$ ], and of $\geq 35$ years old $[\mathrm{AOR}=4.24 ; 95 \%$ CI: $2.54,7.07)]$ were found to have higher odds ratio of tobacco use as compared to reproductive age women of $<25$ years. Regarding their religion, reproductive-age women of protestant religion followers $[\mathrm{AOR}=2.36 ; 95 \% \mathrm{CI}: 4.17$, 9.42], Islamic religion followers $[\mathrm{AOR}=3.92 ; 95 \% \mathrm{CI}$ : $2.16,7.11]$, and traditional religion followers $[\mathrm{AOR}=$ 16.23; 95\% CI: 8.33, 31.61] were found having higher odds ratios of current tobacco use than those Orthodox religion followers.

In this study, the odds of tobacco use increased as the wealth index of reproductive-age women decreased from the

Table 2 Percentage of Reproductive-Age Women Who Currently Use Tobacco Products, Across Their Administrative Regions, Ethiopia DHS 2016 ( $N=15,683)$

\begin{tabular}{|l|c|c|c|}
\hline Characteristics & $\begin{array}{c}\text { Total } \\
\text { Number } \\
\text { of } \\
\text { Women }\end{array}$ & $\begin{array}{c}\text { Number of } \\
\text { Women Who } \\
\text { Currently Use } \\
\text { Tobacco }\end{array}$ & $\begin{array}{c}\text { The Current } \\
\text { Prevalence } \\
\text { of Tobacco } \\
\text { Uses (\%) }\end{array}$ \\
\hline Administrative regions \\
\hline Tigray & 1682 & 0 & 0.00 \\
Afar & 1128 & 29 & 13.36 \\
Amhara & 1719 & 2 & 0.92 \\
Oromia & 1892 & 12 & 5.53 \\
Somali & 1391 & 5 & 2.30 \\
Benishangul & 1126 & 36 & 16.59 \\
SNNPR & 1849 & 12 & 5.53 \\
Gambella & 1035 & 96 & 44.24 \\
Harari & 906 & 8 & 3.68 \\
Addis Ababa & 1824 & 5 & 2.30 \\
Dire Dawa & 1131 & 12 & 5.53 \\
\hline
\end{tabular}

richest to the poorest. Those reproductive age women found in the poorest wealth index [AOR $=15.78 ; 95 \%$ CI: 7.38 , 33.70], poorer wealth index [AOR $=5.85 ; 95 \%$ CI: 2.64 , 12.97], middle wealth index [AOR $=3.61 ; 95 \%$ CI: 1.57 , $8.29]$, and richer wealth index $[\mathrm{AOR}=2.48 ; 95 \% \mathrm{CI}: 1.10$, 5.85] were found having higher odds ratios of current tobacco use than those found in the richest wealth index.

Regarding their current marital status, reproductive-age women who were never in union $[\mathrm{AOR}=0.31 ; 95 \% \mathrm{CI}$ : $0.14,0.67]$ were found to have a lower odds ratio of current tobacco use than those married women. Participants who had a history of ever drinking alcohol $[\mathrm{AOR}=5.44 ; 95 \% \mathrm{CI}: 3.71,7.95]$ and ever chewing khat [AOR $=7.59 ; 95 \%$ CI: $4.99,11.55]$ were also found to have a higher odds ratio of current tobacco use as compared to those who did not ever drink alcohol and who did not ever chew khat respectively (Table 3 ).

\section{Discussion}

This is the first survey to report the current tobacco use and its determinants among Ethiopian reproductive-age women using a representative national wide EDHS 2016 data. This study will provide input to the governments and policy-makers and will help them to evaluate and improve the existing National Tobacco Control Directive especially with a focus on a special group of populations like reproductive-age women.

In this survey, we realized that the national magnitude of current tobacco uses among the 15,683 reproductive-age women in Ethiopia was $1.4 \%$. Tobacco use is still increasing among reproductive-age women as compared with the result of EDHS 2011, which has reported the prevalence of current tobacco use among women age 15-59 years old was $0.8 \%{ }^{8}$ This could be due to the Ethiopian National 
Table 3 Factors Associated with Current Tobacco Use Among the Reproductive Age Women, Ethiopia DHS 2016 (N= I5,683)

\begin{tabular}{|c|c|c|c|c|}
\hline \multirow[t]{2}{*}{ Predictor Variables } & \multicolumn{2}{|c|}{ Current Tobacco Use } & \multirow[t]{2}{*}{ COR $(95 \% \mathrm{Cl})$} & \multirow[t]{2}{*}{ AOR $(95 \% \mathrm{Cl})$} \\
\hline & No & Yes & & \\
\hline \multicolumn{5}{|l|}{ Age group (in years) } \\
\hline$<25$ & 6376 & 25 & I & 1 \\
\hline $25-34$ & 4999 & 87 & $4.44(2.84,6.94)^{*}$ & $2.78(1.69,4.57)^{*}$ \\
\hline$\geq 35$ & 4091 & 105 & $6.55(4.23,10.14)^{*}$ & $4.24(2.54,7.07)^{*}$ \\
\hline \multicolumn{5}{|l|}{ Residence } \\
\hline Urban & 5292 & 56 & I & I \\
\hline Rural & 10,174 & 161 & $1.49(1.10,2.03)^{*}$ & $1.0(0.68,1.47)$ \\
\hline \multicolumn{5}{|l|}{ Educational status } \\
\hline No education & 6906 & 127 & $4.39(1.79,10.76)^{*}$ & $1.05(0.38,2.89)$ \\
\hline Primary & 5158 & 55 & $2.55(1.02,6.37)^{*}$ & $1.36(0.50,3.67)$ \\
\hline Secondary & 2208 & 30 & $3.25(1.26,8.38)^{*}$ & $2.63(0.96,7.23)$ \\
\hline Above & 1194 & 5 & I & 1 \\
\hline \multicolumn{5}{|l|}{ Religion } \\
\hline Orthodox & 6385 & 28 & I & 1 \\
\hline Protestant & 2714 & 100 & $2.56(1.5 \mathrm{I}, 6.8 \mathrm{I})^{*}$ & $2.36(4.17,9.42)^{*}$ \\
\hline Muslim & 6138 & 71 & $2.64(1.70,4.09)^{*}$ & $3.92(2.16,7.11)^{*}$ \\
\hline Others including traditional religion & 229 & 18 & $17.92(9.77,32.88)^{*}$ & $16.23(8.33,31.6 I)^{*}$ \\
\hline \multicolumn{5}{|l|}{ Wealth index } \\
\hline Poorest & 3779 & 115 & |3.32 (6.5।, 27.24)* & I $5.78(7.38,33.70)^{*}$ \\
\hline Poorer & 2015 & 31 & $6.29(2.93,13.48)^{*}$ & $5.85(2.64,12.97)^{*}$ \\
\hline Middle & 1986 & 16 & $3.36(1.49,7.52)^{*}$ & $3.61(1.57,8.29)^{*}$ \\
\hline Richer & 2029 & 13 & $2.66(1.15,6.12)^{*}$ & $2.48(1.10,5.85)^{*}$ \\
\hline Richest & 5657 & 42 & I & I \\
\hline \multicolumn{5}{|l|}{ Current marital status } \\
\hline Never in union & 4270 & 8 & $0.12(0.05,0.22)^{*}$ & $0.31(0.14,0.67)^{*}$ \\
\hline Married & 9656 & 168 & I & 1 \\
\hline Widowed & 431 & 20 & $2.67(1.66,4.28)^{*}$ & $1.38(0.8 \mathrm{I}, 2.37)$ \\
\hline Divorced & 864 & 14 & $0.93(0.54,1.61)$ & $1.28(0.7 \mathrm{I}, 2.29)$ \\
\hline Separated & 245 & 7 & $1.64(0.76,3.54)$ & $1.67(0.73,3.82)$ \\
\hline \multicolumn{5}{|l|}{ Occupation within the last 12 months } \\
\hline No occupation & 9877 & 134 & $0.91(0.69,1.20)^{*}$ & $1.06(0.78,1.43)$ \\
\hline Has occupation & 5589 & 83 & 1 & I \\
\hline \multicolumn{5}{|l|}{ Ever drink alcohol } \\
\hline No & 10,382 & 134 & I & 1 \\
\hline Yes & 5084 & 83 & $1.27(0.96,1.67)^{*}$ & $5.44(3.71,7.95)^{*}$ \\
\hline \multicolumn{5}{|l|}{ Ever chewed khat } \\
\hline No & 13,966 & 161 & I & I \\
\hline Yes & 1500 & 56 & $3.24(2.38,4.4 \mathrm{I})^{*}$ & $7.59(4.99,11.55)^{*}$ \\
\hline
\end{tabular}

Note: *Statistically significant at $p<0.25$ in bivariate and at $p<0.05$ in multivariate logistic regression analysis.

Abbreviations: AOR, adjusted odds ratio; COR, crudes odds ratio; SNNPR, Southern Nations, Nationalities, and People's Region.

Tobacco Control Directive (NTCD) has several weaknesses such as allowing smoking in designated rooms and areas in some workplaces that could be an obstacle to ending tobacco in Ethiopia. ${ }^{29}$ Again the legislation is not wideranging and not successfully applied to warrant its purposes of protecting the community from tobacco threat, and there are no well-defined legal and administrative measures to be taken if the law is not obeyed. ${ }^{30}$

Another point in this survey was that we had tried to look at the magnitude of different types of tobacco use. As 
can be seen from Figure 1, out of the two hundred seventeen current tobacco users, $51(23.5 \%)$ of them chew tobacco. Having data on smokeless tobacco use like chewing tobacco is very important and has input in the way of tobacco control. WHO reported smokeless tobacco use like chewing tobacco had a deficiency of statistics and was monitored in fewer countries than smoking tobacco which means that tobacco use reduction efforts have had a much larger effect on smoking prevalence, allowing chewing tobacco prevalence to remain constant over time. ${ }^{1}$

In this study also, there is variation in the distribution of tobacco use among reproductive-age women across administrative regions of Ethiopia. The uppermost prevalence found in the Gambella region, Benishangul, and Afar regional states respectively, and the possible reason behind this could be the accessibility of illegal import cigarettes. ${ }^{8}$ The other reason might be due to variations in the study settings, such as access to different substances and the sociocultural nature of the populations. For instance, in the eastern part of Ethiopia including afar and Harar, and other borderline regions of Ethiopia like Gambella and Benishangul region, substances like chewing khat and smoking cigarettes are more common and are socially acceptable as well as a behavior learned from parents, older siblings, and neighbors. $^{31,32}$ However, in this survey, there was no reported recent tobacco practice by reproductive-age women from Tigray regional state. Knowing such regions with high tobacco use is very important and helps the concerned bodies regarding their efforts to reduce tobacco use in the country.

Our study revealed as the age of reproductive age women increased, the odds ratio of current tobacco uses also increased which means the oldest women have a higher odds ratio of current tobacco use than the youngest women. This result was in line with the previous studies in Ethiopia, Tanzania, Brazil, and Burkina Faso. ${ }^{8,23,33-35}$ In contrast, a study in Kenya reported that the majority of smokers were in younger age groups. ${ }^{36}$ The reason for higher tobacco use in older women could be due to older women might have long smoking histories, previous unsuccessful quitting attempts, and doubts about the advantages of leaving tobacco use. ${ }^{37}$ In this study, regarding the participants' religion, the odds ratio of current tobacco uses are particularly increased in women from traditional religion. This finding was supported by the prior study. ${ }^{38}$ The reason behind as indicated in the previous study was, religious involvement is inversely related to tobacco use. Religiously active persons are less likely to smoke cigarettes, and if they do smoke, smoke fewer cigarettes. $^{38,39}$

The odds ratio of current tobacco use increased as the wealth index of reproductive age women decreased from richest to poorest, and this finding was supported by a previous study finding in India. ${ }^{40}$ One of the possible reasons behind this could be the bilateral relationship between being poor and tobacco use. This means that being poor can lead to tobacco use, and also, tobacco use can increase poverty. The other probably is that the poorest people might use tobacco for self-medication like to normalize their moods, resistor stress, and deal with the tensions of material deprivation. ${ }^{41,42}$

Regarding their current marital status, reproductive-age women who were never in a union were found to have low odds ratios of current tobacco use than those married women, and this result was consistent with the study finding from India. ${ }^{40}$ This finding could be due to marital status, and age is usually closely linked. In our study, we found that older women have higher odds ratios of current tobacco use than the youngest reproductive-age women. Again reproductive-age women who were never in a union could be more likely young age that might decrease their odds ratios of current tobacco use. ${ }^{41}$

Our study revealed that participants who had a history of ever drinking alcohol were found to have higher odds ratios of current tobacco use than those who did not ever drink alcohol. Similarly, respondents who had a history of ever chewing khat were also found to have higher odds of current tobacco use than those who did not ever chew khat. This finding was consistent with many previous study results. ${ }^{22,33,40}$ This can be due to poly-substance use behaviors. Khat chewing, alcohol consumption, and tobacco use are closely connected ceremonies, and consuming one of them could lead to the use of another one. For instance, people who drink more amounts of alcohol tend to smoke more cigarettes. Moreover, people who were dependent on nicotine have higher odds of being alcohol dependent than nonsmokers. ${ }^{43}$ This finding indicates that tobacco control cannot be realized alone, without controlling khat and alcohol use.

\section{Strengths and Limitations}

The strength of this study is that we analyzed data from a nationwide survey, which comprises a representative sample. Besides, this study result revealed the magnitude of different forms of tobacco use including non-smokeless tobacco use like chewing tobacco which was usually 
overlooked worldwide but plays a significant role in tobacco control efforts. In contrast, this study has some limitations. First, EDHS secondary data we used has missed some important variables like the history of mental illness, parental hostility, strictness, and family conflict, level of parental supervision, involvement, or attachment, and partners or other household members' smoking cigarettes. Second, substance use is usually a sensitive issue in many cultures due to its associated stigma. So, this study could be affected by a social desirability bias, and the reported tobacco use can be below the expected one. Third, this study assessed only the prevalence of current tobacco use at the time of the EDHS and did not have the lifetime prevalence of tobacco use. Fourth, we did not consider the complex sampling of the DHS surveys and we did not use the complex sampling specifications in the estimates of the results. Finally, we used odds ratios instead of prevalence ratios because we did not use advanced analysis models like Cox or Poisson regression with robust variance and log-binomial regression which are a better alternative for the analysis of cross-sectional studies with binary outcomes than logistic regression.

\section{Conclusion}

Tobacco is used not only in smoking forms but also in smokeless forms like chewing. Tobacco is highly used, in some specific regional states like Gambella, Benishangul, and Afar. Variables including age, religion, wealth index, current marital status, ever drink alcohol, and ever chewed chat were significantly associated with tobacco use. Regions with higher tobacco use need special attention, and possible related factors like contraband cigarettes in these regions need to be controlled. Tobacco-focused prevention strategies and interventions among reproductiveage women are required. For instance, providing women with information on the risks of tobacco use especially adverse outcomes of tobacco use in pregnancy to both mother and baby, evaluation of tobacco uses and other substance use among antenatal women to identify harmful use and to promote cessation and/or to provide necessary interventions among user to overcome the adverse outcomes is mandatory. Besides, evaluating and restricting the existing National Tobacco Control Directive especially among reproductive-age women is very important.

\section{Data Sharing Statement}

This study utilized the National EDHS of 2016 [Dataset] which can be accessed on (http://idhsdata.org). The datasets used and/or analyzed in the current study are available from the corresponding author on reasonable request.

\section{Ethical Consideration}

DHS data were originally collected in conventionality with national and international ethical guiding principles. The original survey was given ethical clearance by the Ethiopian Public Health Institute Review Board, the National Research Ethics Review Committee (NRERC) at the Ministry of Science and Technology, the Institutional Review Board of ICF International, and the Centers for Disease Control and Prevention (CDC). The data for this research were downloaded from the publicly available dataset on the EDHS website (https://dhsprogram.com/) after registering with the DHS website and after we received a permission letter for access to this database from Measure DHS, ICF International, Rockville, Maryland, USA. Besides, ethical approval was obtained from the Institutional Health Research Ethics Review Committee (IHRERC) of Haramaya University, College of Health and Medical Sciences to conduct this study. The acquired Data was kept anonymized and we used it only for statistical reporting and analysis. There were no names of individuals or household addresses in the data files.

\section{Acknowledgment}

The authors acknowledged Measure DHS for granting the data for this study.

\section{Author Contributions}

All authors made a significant contribution to the work reported, whether that is in the conception, study design, execution, acquisition of data, analysis and interpretation, or in all these areas; took part in drafting, revising or critically reviewing the article; gave final approval of the version to be published; have agreed on the journal to which the article has been submitted; and agree to be accountable for all aspects of the work.

\section{Disclosure}

The authors declare that they have no competing interests.

\section{References}

1. World Health Organization. WHO report on the global tobacco epidemic, 2019 [Internet]. World Health Oraganization; 2019 [cited February 12, 2020]. Available from: http://www.who.int/tobacco/glo bal_report/en/. Accessed March 9, 2021.

2. Kaplan BJ. Kaplan and Sadock's synopsis of psychiatry. Behavioral sciences/clinical psychiatry. Tijdschr Psychiatr. 2016;58(1):78-79. 
3. World Health Organization. WHO report on the global tobacco epidemic, 2017: monitoring tobacco use and prevention policies. World Health Organization; 2017. Available from: https://apps.who.int/iris/ handle/10665/255874. Accessed March 9, 2021. License: CC BY-NC -SA 3.0 IGO.

4. Women and smoking: a report of the surgeon general (Executive Summary). Atlanta: Centre for Disease Control and Prevention; 2002.

5. Judith M, Amanda A. Women, and tobacco. Respirology. 2003;8:123-130. doi:10.1046/j.1440-1843.2003.00464.x

6. Barakoti R, Ghimire A, Pandey AR, Baral DD, Pokharel PK. Tobacco Use During Pregnancy and its Associated Factors in a Mountain District of eastern Nepal: a cross-sectional questionnaire survey. Front Public Health. 2017;5:129. doi:10.3389/ fpubh.2017.00129

7. Magitta N. Epidemiology of tobacco use and dependence in Sub-Saharan Africa: a systematic review. J Pulmonol Clin Res. 2018;2(1).

8. Lakew Y, Haile D. Tobacco use and associated factors among adults in Ethiopia: further analysis of the 2011 Ethiopian Demographic and Health Survey. BMC Public Health. 2015;15:487. doi:10.1186/ s12889-015-1820-4

9. Ethiopia G. Global adult tobacco survey: executive summary; 2016.

10. Kitaw Y. Socioeconomic and cultural implications of health interventions: the case of smoking in Ethiopia. J Public Health Policy. 1986;7 (2):198-204. doi:10.2307/3342257

11. Kulkarni N, Hawal N, Naik VA. Tobacco use among rural women in reproductive age group and its association with the regularity of menstrual cycles and dysmenorrhoea: a community-based cross-sectional study. Int J Commun Med Public Health. 2017;5 (1):210. doi:10.18203/2394-6040.ijcmph20175784

12. Quelhas D, Kompala C, Wittenbrink B, et al. The association between active tobacco use during pregnancy and growth outcomes of children under five years of age: a systematic review and meta-analysis. BMC Public Health. 2018;18(1):1372. doi:10.1186/ s12889-018-6137-7

13. Rozi S, Butt ZA, Zahid N, Wasim S, Shafique K. Association of tobacco use and other determinants with pregnancy outcomes: a multicentre hospital-based case-control study in Karachi, Pakistan. BMJ Open. 2016;6(9):e012045. doi:10.1136/bmjopen-2016-012045

14. Indu B, Ahluwalia LG-S, Kelley S. Scanlon. exposure to environmental tobacco smoke and birth outcome: increased effects on pregnant women aged 30 years or older. Am J Epidemiol. 1996;146(1).

15. Cornelius MD, Day NL. The effects of tobacco use during and after pregnancy on exposed children: relevance of findings for alcohol research. Alcohol Res Health. 2000;24(4):242.

16. World Health Organization. Impact of tobacco use on women's health- WHO. Gender, Women, and the Tobacco Epidemic.

17. World Health Organization. WHO framework convention on tobacco control. World Health Organization: Geneva, Switzerland; 2003.

18. World Health Organization. Ethiopia ratifies WHO framework convention on tobacco control; 2014. Available from: https:/www.afro. who.int/news/ethiopia-ratifies-who-framework-convention-tobaccocontrol. Accessed January 13, 2015

19. Union A. The impact of tobacco use on health and socio-economic development in Africa. A status reports tobacco use on health and socio-economic development in Africa; 2012.

20. Khatri R, Mishra S, Khanal V. Tobacco use among rural Nepalese women: cross-sectional community-based study. Indian J Cancer. 2015;52(4):699. doi:10.4103/0019-509X.178412

21. Office o, Smoking, and Health (US). Factors influencing tobacco use among women. Women and Smoking: A Report of the Surgeon General. US: Centers for Disease Control and Prevention; 2001.

22. Guliani H, Gamtessa S, Cule M. Factors affecting tobacco smoking in Ethiopia: evidence from the demographic and health surveys. $B M C$ Public Health. 2019;19(1):938. doi:10.1186/s12889-019-7200-8
23. Schoemaker N, Hermanides J, Davey G. Prevalence and predictors of smoking in Butajira town, Ethiopia. Ethiop J Health Dev. 2005;19(3).

24. Giovino GA, Biener L, Hartman AM, et al. Monitoring the tobacco use epidemic I. Overview: optimizing measurement to facilitate change. Prev Med. 2009;48(1 Suppl):S4-10. doi:10.1016/j. ypmed.2008.08.007

25. Girma GG. Ethiopia: brief history, energy demand and its implication on environment.

26. Turi E, Merga BT, Fekadu G, Abajobir AA. Why too soon? Early initiation of sexual intercourse among adolescent females in Ethiopia: evidence from 2016 Ethiopian Demographic and Health Survey. Int $J$ Women's Health. 2020;12:269. doi:10.2147/IJWH.S244621

27. Getahun MB, Nigatu AG. Knowledge of the ovulatory period and associated factors among reproductive women in ethiopia: a population-based study using the 2016 Ethiopian demographic health survey. Int J Women Health. 2020;12:701. doi:10.2147/IJWH.S267675

28. Recommendation P. STROBE Statement-Checklist of items that should be included in reports of cross-sectional studies. Available from: http://www.equator-network.org/wpcontent/uploads/2015/10/ STROBE_checklist_v4_cross-sectional.pdf. Accessed March 9, 2021

29. Erku DA, Tesfaye ET. Tobacco control and prevention efforts in Ethiopia pre- and post-ratification of WHO FCTC: current challenges and future directions. Tob Induc Dis. 2019;17. doi:10.18332/tid/ 102286

30. Shona E. Banning smoking in public places under Ethiopian legal framework: some evidence from Hawassa City. Beijing Law Rev. 2017;08(04):526-550. doi:10.4236/blr.2017.84029

31. Gedif T, Azale T, Nigusie A. Substance use and associated factors among Gumuz people in Benishangul-Gumuz regional state, Mandura woreda, Northwest Ethiopia. Subst Abuse Treat Prev Policy. 2019;14(1):1-9. doi:10.1186/s13011-019-0225-2

32. Lemessa D. Khat botany, distribution, cultivation, usage, and economics in Ethiopia. Un-Eue; 2001.

33. Bonnechere B, Cisse K, Millogo T, et al. Tobacco use and associated risk factors in Burkina Faso: results from a population-based cross-sectional survey. BMC Public Health. 2019;19(1):1466. doi:10.1186/s12889-019-7826-6

34. Peixoto SV, Firmo JO, Lima-Costa MF. Factors associated to smoking habit among older adults (The Bambuí Health and Aging Study). Rev Saúde Pública. 2005;39(5):745-753. doi:10.1590/S003489102005000500008

35. Jagoe K, Edwards R, Mugusi F, Whiting D, Unwin N. Tobacco smoking in Tanzania, East Africa: population-based smoking prevalence using expired alveolar carbon monoxide as a validation tool. Tob Control. 2002;11:210-214.

36. Ngaruiya C, Abubakar H, Kiptui D, et al. Tobacco use and its determinants in the 2015 Kenya WHO STEPS survey. BMC Public Health. 2018;18(Suppl 3):1223. doi:10.1186/s12889-018-6058-5

37. Donze J, Ruffieux C, Cornuz J. Determinants of smoking and cessation in older women. Age Ageing. 2007;36(1):53-57. doi:10.1093/ ageing/afl120

38. Koenig HG, George LK, Cohen HJ, Hays JC, Larson DB, Blazer DG. The relationship between religious activities and cigarette smoking in older adults. J Gerontol a Biol Sci Med Sci. 1998;53(6):M426-M434. doi:10.1093/gerona/53A.6.M426

39. Wang Z, Koenig HG, Al Shohaib S. Religious involvement and tobacco use in mainland China: a preliminary study. BMC Public Health. 2015;15(1):1-9. doi:10.1186/s12889-015-1478-y

40. Manimunda P, Benegal V, Sugunan A, et al. Tobacco use and nicotine dependency in a cross-sectional representative sample of 18,018 individuals in Andaman and Nicobar Islands, India. BMC Public Health. 2012;12(1):515. doi:10.1186/1471-2458-12-515

41. World Health Organization. Tobacco and poverty a vicious circle; 2004. Available from http://www.who.int/tobacco/communications/ events/wntd/2004/en/wntd2004_brochure_en.pdf. Accessed March 9, 2021. 
42. Graham H. Gender and class as dimensions of smoking behavior in Britain: insights from a survey of mothers. Soc Sci Med. 1994;38 (5):691-698. doi:10.1016/0277-9536(94)90459-6
43. Breslau N. Psychiatric comorbidity of smoking and nicotine dependence. Behav Genet. 1995;25(2):95-101. doi:10.1007/BF021 96920

\section{Publish your work in this journal}

Substance Abuse and Rehabilitation is an international, peerreviewed, open access journal publishing original research, case reports, editorials, reviews and commentaries on all areas of addiction and substance abuse and options for treatment and rehabilitation. The

manuscript management system is completely online and includes a very quick and fair peer-review system. Visit http://www.dovepress. com/testimonials.php to read real quotes from published authors. 